\title{
Approaching Pharmaceutical Patent Enforcement Using Intellectual Property Rights and Product Innovation
}

\author{
Soaad Q. Hossain \\ Department of Philosophy, Department of Computer and Mathematical Sciences, \\ University of Toronto, Canada
}

\section{Introduction}

An ongoing debate that continues to persist till date is the debate on whether pharmaceutical corporations should be allowed to enforce their patents in the developing world to prevent the manufacturing of generic versions of their drugs. In this paper, I will discuss the intellectual property rights perspective on pharmaceutical patents that supports the enforcement of patents by pharmaceutical corporations, then global justice perspective on pharmaceutical patents that opposes the enforcement of patents by pharmaceutical corporations. From there, I will conclude with a product innovation-based argument against the enforcement of patents by pharmaceutical corporations.

\section{Human and Property Rights}

As patents are a type of intellectual property, the argument for pharmaceutical corporations being allowed to enforce their patents in the developing world to prevent the manufacturing of generic versions of their drugs is more an argument for intellectual property which can be translated to patenting. Within Joseph Millum's article Are Pharmaceutical Patents Protected by Human Rights, he states that two comments from the Committee on Economic, Social and Cultural Rights that can be used to approach health rights and intellectual property. The first comment made by the committee, article 15 (1) (c), essentially states that the rights of the creator that made the intellectual property are to be protected of the moral and material interests resulting from that intellectual property. The second comment made by the committee, article 17, essentially states that one's intellectual property should not be prioritized over one's rights to food, health and education, implying that one's intellectual property rights are not human rights, and should be overridden by human rights claims pertaining to food, health and education. The first comment implies that intellectual property is to be protected. The second comment implies that health rights should be prioritized over intellectual property protection and their creator's rights (Millum, 2008). Consequently, this leads to a conflict when it comes to cases such as of pharmaceutical patents.

Even with the conflict, one major reason why intellectual property rights and protection triumphs human rights, including health rights, is because while it is true that particular intellectual property rights have properties not possessed by human rights, it is not true that the right to acquire or hold intellectual property 
is likewise different (Millum, 2008). As such, when considering intellectual property rights versus human rights from legal regimes, given the rights surrounding protection of intellectual property, International Bill of Rights and legal mechanisms focusing on possession of property, legal regimes would support more rights of intellectual property than human rights, leading to human rights claims not overriding or taking precedents over intellectual property rights and protection. What can be concluded is that intellectual property rights would be supported more within legal regimes, this will favor pharmaceutical corporations enforcing their patents. As legal regimes support intellectual property rights more than human rights, then pharmaceutical corporations can and are allowed to exert their intellectual property rights.

\section{Global Justice and Patenting}

In considering the global justice argument against pharmaceutical corporations being allowed to enforce their patents in the developing world to prevent the manufacturing of generic versions of their drugs, we consider the arguments made by Mihail-Valentin Cernea and Radu Uszkai in their article The Clash between Global Justice and Pharmaceutical Patents: A Critical Analysis. In this article, they state how intellectual property rights and patents are justified on the grounds of natural rights arguments, then addresses how such justification fails in two ways.

The first way it that the natural rights approach fails as it resides in the arbitrariness of granting or not granting a patent. Scientific discoveries are not creations of a researcher or scientists but are merely a discovery of a certain phenomenon from the objective world (Cernea \& Uszkai, 2012). In not considering this realization, this creates problems for drug patenting as given that drugs rely on scientific discoveries and scientific discoveries cannot be patented, therefore drugs created by pharmaceutical corporations cannot be patented. However, as the authors highlighted, the latter type of intellectual property or product are patentable (Cernea \& Uszkai, 2012). This leads to confusion and unclarity on whether patenting such as drug patenting is permissible, leading to the granting of patents being arbitrary. The second way it that the natural rights approach fails as it does not take into account the fact that the person that has ownership of the material and knowledge that was used to create the product is different from the person that created the product. As such, just because someone created a product out of the material and knowledge, that does not mean that the creation is theirs. The example that Cernea and Uszkai used is that of raw material and a sword. An example that I will use is that of a corporation and a scientist in a corporation. As much as a scientist that creates a product within a corporation should have full rights over the patent of that product, the reality is that they will not have full rights over it because they used the material and technology owned by the corporation. As a result, the rights over the patent of the product are shared between both the scientist and the corporation. As we can see, the natural rights approach fails to incorporate 
the fact that the person that has ownership of the material and knowledge that was used to create the product is different from the person that created the product, which this along with the previous issue of the arbitrariness of patenting products essentially provides grounds to reject the human rights argument for enforcement of patents by pharmaceutical corporations.

\section{Product Innovation}

A strong reason why pharmaceutical corporations should not be allowed to enforce their patents is because their generic drugs are not true creation or innovation. They are based on what I call "innovative recycling". In this context, innovative recycling is reusing a drug that already exits along with a therapy or treatment that already exists, and combining the two with hopes that the resulting product leads to a drug discovery. From a first glance, the resulted product can be seen as an innovation. However, when further investigating it, we will find that unlike other innovated products, the resulted product does not contain an element of unnaturalness to it. When I say an element of unnaturalness, I mean some sort of element that is uncommon and extraordinary. Before elaborating on why generic drugs do not have an unnatural element to it, it is important to understand what role the element plays in product innovation. To help understand this, I will provide an example involves a patented innovation by IBM.

Consider the IBM patent polycarbonates bearing aromatic $N$-heterocycles for drug delivery. The innovation itself is nanoparticles that are capable of controlled released of a drug in a medical treatment (Justia, 2017). Without getting too much into the science of polycarbonate, what is important to know about it is that is a high-performance tough, amorphous and transparent thermoplastic polymer that is often used in clinical and diagnostic settings in which visibility of tissues, blood and fluids are required (Powell, 1998). Aromatic N-heterocycles comes from aromatic N-heterocyclic compounds chemicals that is very important as their motifs (i.e. pattern of amino acid) are found in many natural products, pharmaceutical products, and functional material (Qi et al., 2019). While some may argue that in considering polycarbonate and Aromatic N-heterocycles separately as two products providing solutions to medical problems, combining the two is just innovative recycling, the reality is that it is not. What makes this innovation an innovation is its element that is uncommon and extraordinary. Since polycarbonates bearing aromatic $\mathrm{N}$-heterocycles for drug delivery is made up of a thermoplastic polymer and polymers in general are non-biodegradable (Justia, 2017), it is not supposed to be biodegradable. However, the fact that polycarbonates bearing aromatic $\mathrm{N}$-heterocycles for drug delivery is biodegradable is what makes the innovation uncommon, and even extraordinary. Furthermore, the fact it is noncytotoxic (i.e. not toxic to human cells) and prevents a drug from prematurely releasing before reaching an intended cell target (Justia, 2017) is what makes it extraordinary. As such, polycarbonates bearing aromatic N-heterocycles for 
drug delivery is an innovation that would not only be appropriate for patenting, but can also be a patent that can be enforced on others. Accordingly, this would allow IBM to enforce that patent on others.

Where generic versions of drugs differ from an innovation or creation like IBM's innovation is that it lacks the uncommon and extraordinary element. Generic drugs are based on natural origins and natural products. In the case of anticancer drugs and anti-infectious disease drugs, it has been reported in a study that $60 \%$ of the anticancer drugs and $75 \%$ of the anti-infectious disease drugs approved from 1981 to 2002 could be traced to natural origins (Gupta, Gabrielsen \& Ferguson, 2005). Additionally, if we were to look into today's best-selling drugs, we will find that their creation and development connects to traditional knowledge (Dutfield, 2010). These tell us that there is no uncommon element in generic drugs like there was for IBM's innovation. Furthermore, with the generic drugs being based on things that have already succeeded when used for therapy and treatment and not taking a step further in accomplishing more like what IBM's innovation did (through making their innovation biodegradable), it is expected that the generic drugs will achieve something that is not out of the ordinary. Consequently, this expectation leads to the loss of extraordinariness in the generic drug. Therefore, with the generic drugs not having the unnaturalness element to it makes them not true creations or innovations. In reaching this conclusion, we can conclude that not only should pharmaceutical corporations not be allowed to enforce their patents in the developing world to prevent the manufacturing of generic versions of their drugs, but they should not be allowed to enforce their patents on anyone.

\section{Closing Remarks}

One thing that may be noticed with the product innovation-based argument is that it can be connected to Cernea and Uszkai argument regarding scientific discoveries and pharmaceutical drugs and concluding that granting of patents being arbitrary. The product innovation-based argument essentially adds on their argument. With that being said, the global justice argument is a stronger argument than that of intellectual property rights because it directly addresses what drugs are, enabling one to easily understand how they are neither a creation nor an innovation, therefore making it more convincing to why drugs should not be considered for patenting. Combining this with the product innovation-based argument and the IBM innovation example provides it even more for why pharmaceutical corporations should not be allowed to enforce their patents in the developing and developed world to prevent the manufacturing of generic versions of their drugs. Through making the case that generic drugs are not creations nor innovations, this approach to intellectual property rights involving generic drugs is better than using the health rights argument as the approach addresses the core problem with generic drugs in a way that, once that problem is solved, there will no longer be drug patent enforcement issues ever. Once generic drugs are no longer considered creations or innovation, then 
pharmaceutical corporations will no longer be able to enforce their patents, leading to more health-related opportunities and health rights of people being respected.

\section{References}

Cerna M., \& Uszkai R. 2012. The Clast between Global Justice and Pharmaceutical Patents: A Critical Analysis. Public Reason. 4. 1-2. $210-221$.

Dutfield G. 2010. Why Traditional Knowledge is Important in Drug Discovery. Future Med. Chem. 2. 9. 1405 -1409.

Gupta R., Gabrielsen B., \& Ferguson S. M. 2005. Nature's Medicines: Traditional Knowledge and Intellectual Property Management. Case Studies from the National Institute of Health (NIH), USA. Curr Drig Discov Technol. 2. 4. 203 - 2019.

Justia. 2017. Polycarbonates Bearing Aromatic N-heterocycles for Drug Discovery. Retrieved on April 4, 2020 from:

https://patents.justia.com/patent/10610597

Millum J. 2016. Are Pharmaceutical Patents Protected by Human Rights? J Med Ethics. 34. 11. 1 - 8.

Powell D. G. 1998. Medical Applications of Polycarbonate. Medical Device and Diagnostic Industry. Retrieved on April 6, 2020 from: https://www.mddionline.com/medical-applications-polycarbonate

Qi Y., Kou Y., Pang H., Zhang S., Li N., Liu C., Weng Z., \& Jian X. Synthesis of an Aromatic N-Heterocycle Derived from Biomass and its Use as a Polymer Feedstock. Nature Communications. 10. 2107 (2019). 1 - 2. 